\title{
RPG DIGITAL: PROPOSTA DE QUALIFICAÇÃO PROFISSIONAL DOS POLICIAIS MILITARES DO ESTADO DA BAHIA PARA ATUAÇÃO NOS PROBLEMAS RELACIONADOS AO USO INDEVIDO DAS DROGAS POR CRIANÇAS E ADOLESCENTES.
}

\author{
SALVADOR/BA JULHO/2018
}

\author{
IGOR BACELAR DA CRUZ URPIA - UFBA - igorurpia@yahoo.com.br \\ ALFREDO EURICO RODRIGUES MATTA - UNEB - alfredo@matta.pro.br
}

Tipo: Investigação Científica (IC)

Natureza: Descrição de Projeto em Andamento

Categoria: Métodos e Tecnologias

Setor Educacional: EDUCAÇÃO CORPORATIVA

\begin{abstract}
RESUMO
O presente artigo visa discutir uma nova estratégia de ensino-aprendizagem na Polícia Militar do Estado da Bahia (PMBA), com o intuito de proporcionar uma qualificação mais abrangente, frente à atuação relacionada aos problemas referentes ao uso indevido das drogas por crianças $e$ adolescentes, questão esta que se constitui em uma das principais causas da evasão escolar. Nessa perspectiva, a PMBA, desde 2003, desenvolve as ações do Programa Educacional de Resistência às Drogas e à Violência (PROERD), com o objetivo de qualificar policiais militares para trabalharem com a temática em salas de aula escolar. Contudo, a qualificação profissional no referido programa demanda um custo elevado. Desse modo, surge a proposta em questão, a qual visa, através do RPG (Role Playing Game), proporcionar a PMBA um ambiente virtual de aprendizagem interativo e colaborativo. $A$ abordagem metodológica DBR (Design-based Research) será a utilizada para o desenvolvimento da pesquisa e para a construção do RPG Digital, o qual é um software que se constitui em um ambiente educacional de aprendizagem, modelado a fim de proporcionar um espaço destinado à construção cognitiva e difusão do conhecimento proposto, favorecendo práticas de ensino-aprendizagem baseadas no socioconstrutivismo, que preceitua que a construção do conhecimento é estabelecida através de uma relação dialética entre os sujeitos e o contexto social.
\end{abstract}

Palavras-chave: Polícia Militar. Prevenção das Drogas. RPG Digital. Qualificação Profissional. 


\section{Introdução}

Atualmente, uma das principais causas da evasão escolar está diretamente ligada ao uso de drogas lícitas e/ou ilícitas por crianças e adolescentes, tornando necessária a existência de medidas que vise os conscientizar dos malefícios causados pelo uso indiscriminado de tais substâncias.

Neste artigo, o uso abusivo de psicotrópicos não é visto apenas como uma questão de saúde pública, mas sim como uma questão transversal, pois envolvem as áreas da saúde, segurança pública e, sobretudo da educação, necessitando assim da intervenção de diversos segmentos do Estado e da sociedade, em um esforço colaborativo. (URPIA, 2017).

Nesta perspectiva, aliado a filosofia de polícia comunitária, a polícia militar da Bahia vem desenvolvendo as ações do PROERD (Programa Educacional de Resistência às Drogas e à Violência), o qual consiste na capacitação de policiais militares para trabalharem em salas de aula temas relacionados à conscientização das crianças e adolescentes. Entretanto, por diversas razões, esta capacitação torna-se seletiva e dispendiosa.

A partir dos estudos desenvolvidos no Doutorado Multi-institucional e Multidisciplinar em Difusão do Conhecimento (DMMDC), da Universidade Federal da Bahia, bem como das reuniões do Grupo de Pesquisa "Sociedade em Rede, Pluralidade Cultural e Conteúdos Digitais Educacionais", sob liderança de Alfredo Matta, surge o interesse na pesquisa ora apresentada, uma vez que o Role Playing Game (RPG), enquanto instrumento de mediação educacional, poderá proporcionar a PMBA um ambiente virtual de aprendizagem interativo e colaborativo, ofertando uma qualificação profissional a baixo custo e uma ampla difusão de conhecimento, proporcionada pela plataforma virtual.

Sendo assim, apresentaremos neste artigo as primeiras impressões da pesquisa de doutorado em andamento, tecendo considerações a partir do lastro teórico e metodológico utilizado.

\section{Prevenção ao uso indevido das drogas por crianças e adolescentes}

A Organização Mundial de Saúde - OMS (1981) define droga como qualquer substância que, não produzida pelo organismo, possua a capacidade de atuar sobre um ou mais de seus sistemas, produzindo alterações em seu funcionamento.

As drogas são denominadas psicoativas por atuarem no cérebro, afetando a atividade 
mental do indivíduo, desencadeando diversas alterações no organismo. Silveira e Silveira conceituam droga como sendo [...] "substâncias psicoativas utilizadas para produzir alterações nas sensações, no grau de consciência ou no estado emocional." (2014, p. 70).

Apesar da atual preocupação do uso indiscriminado de substâncias entorpecentes, devese levar em consideração que o consumo de substâncias psicoativas está vinculado à história da humanidade. Todas as culturas, civilizações, fizeram uso de certos produtos que proporcionassem a mudança do estado normal de consciência. Uso esse ligado ao contexto sociocultural, pois os meios de controle sociais, sejam em formatos de leis ou apenas os costumes de cada localidade, ditam, de certo modo, a maneira em que as drogas serão encaradas pela sociedade. (MACRAE, 2014).

Muito embora o uso de substâncias psicoativas sempre estivesse presente na história da humanidade, somente a partir do século XX a sociedade começou a enfrentar com angústia o problema da drogadição, pois o uso deixou de ser atrelado às questões religiosas e culturais, e passou a ser utilizado como alternativa de fuga da realidade, dentro de uma sociedade capitalista perversa, de consumo desenfreado, o que ocasionou uma série de conseqüências sociais.

A Lei $n^{\circ}$ 11.343, de 23 de agosto de 2006, que institui o Sistema Nacional de Políticas Públicas sobre Drogas, descentralizou as ações de prevenção ao uso indevido das drogas, compartilhando as responsabilidades entre o governo federal, estados, municípios e com os diversos segmentos da sociedade civil organizada, em um esforço colaborativo.

Pensamento esse que coaduna com a filosofia de polícia comunitária, pois de acordo com Trojanowicz e Bucqueroux (1999) o policiamento comunitário é definido como sendo:

"[...] uma filosofia e uma estratégia organizacional que proporciona uma nova parceria entre a população e a polícia. Baseia-se na premissa de que tanto a polícia quanto a comunidade devem trabalhar juntas para identificar, priorizar e resolver problemas contemporâneos tais como crime, drogas, medo do crime, desordens físicas e morais, e em geral a decadência do bairro, com o objetivo de melhorar a qualidade geral da vida na área." (TROJANOWICZ; BUCQUEROUX, 1999, p. 4, grifo nosso).

Nesse modelo de policiamento as responsabilidades são compartilhadas e todos os membros da sociedade devem contribuir com a polícia, visando o bem estar coletivo. 
A razão do recorte de trabalhar com crianças e adolescentes se justifica por compreender que nessa fase da vida o corpo humano passa pelas maiores transformações do organismo, como também da formação da personalidade. Assim, nesse momento de mudanças bruscas, de se auto conhecer, a criança e o adolescente estão em situação de vulnerabilidade. (MORAES, 2014).

Moraes aponta que:

[...] apesar da postura cuidadosa dos pais, a proximidade com o tráfico acaba por seduzilos com o imediatismo do acesso ao dinheiro, ao reconhecimento e às experiências proibidas e, por isso mesmo, atrativas. Aos olhos do tráfico, as crianças e adolescentes são oportunidades, seja como consumidores, seja como trabalhadores na enorme rede de distribuição e segurança que precisam constituir. A política de proibição das drogas exige a montagem de um "exército" de soldados do tráfico que precisa também ser constantemente reposta, tanto em função da morte precoce quanto do encarceramento dos agentes da ponta do processo. Esse "exército é composto por crianças, adolescentes e jovens da periferia, geralmente negros e de baixíssima escolaridade". (MORAES, 2014, p. 275, grifo nosso).

Diante de tal circunstância, tornam-se imprescindíveis ações coordenadas entre os poderes públicos, da União, dos Estados e dos Municípios, juntamente com a participação da sociedade, para criar alternativas de enfrentamentos dos problemas relacionados ao uso indevido das drogas por crianças e adolescentes.

A PMBA através das ações do PROERD vem contribuindo nesse sentido. O PROERD tem como modelo o programa norte-americano intitulado de D.A.R.E. - Drug Abuse Resistance Education (Educar para resistir ao abuso de drogas), criado pela professora Ruth Rich, e desenvolvido na cidade de Los Angeles, Califórnia, Estados Unidos da América, no ano de 1983, por uma equipe multidisciplinar, composta por psicólogos, psiquiatras, pedagogos e policiais, sendo aplicado pelo Departamento de Polícia de Los Angeles, em parceria com o Distrito Unificado Escolar daquela cidade. Devido à aceitação obtida socialmente, todos os Estados norte-americanos aderiram ao programa e atualmente 49 países já desenvolvem ações baseadas no D.A.RE.

No Brasil, a proposta do D.A.R.E. foi implantada no ano de 1992, através da Polícia Militar do Estado do Rio de Janeiro, seguida pela Polícia Militar do Estado de São Paulo, em 1993, que após a participação de seus agentes em cursos ministrados pelo Centro de Treinamento do D.A.R.E. de Los Angeles/EUA, passou a adotar a proposta, a qual foi denominada em português de PROERD. 
No Estado da Bahia, o contato com o PROERD teve início no ano de 1998, quando oito oficiais realizaram o Curso de Instrutor no Estado de São Paulo. Entretanto, sua aplicação só se tornou possível em 2003, após a capacitação da primeira turma de Instrutores, em Salvador, com 30 policiais militares formados.

As atividades do PROERD são realizadas por policiais militares no ambiente escolar, desenvolvendo ações baseadas na relação entre a Escola, a Polícia Militar e a Família, visando fomentar o diálogo entre as partes e proporcionar uma visão crítica dos malefícios causados pelas drogas, criando uma rede protetiva.

Contudo, apenas os Estados conveniados ao D.A.R.E América, proprietária dos direitos autorais e intelectuais do PROERD, poderão ofertar o Curso de Formação de Instrutores. Atualmente no Brasil só existem oito polícias militares com equipes de facilitação autorizadas a ministrarem o curso, a saber: Rio de Janeiro, São Paulo, Distrito Federal, Santa Catarina, Minas Gerais, Rio Grande do Norte, Rio Grande do Sul e Pernambuco. Assim, todos os policiais militares do Estado da Bahia que possuem o referido curso foram capacitados em um desses centros de formação, o que torna uma capacitação dispendiosa e seletiva. Cabe ainda ressaltar que este é o único curso sobre a temática oferecido pela Polícia Militar da Bahia aos seus agentes.

Assim, tendo em vista o desenvolvimento de um recurso educacional que proporcione um amplo alcance de qualificação profissional dentro da PMBA, justifica-se utilizar o RPG enquanto instrumento de aprendizagem.

\section{RPG digital: estratégia de capacitação profissional na PMBA}

O Role Playing Game tem sua origem na década de 70, nos Estados Unidos da América, com inspiração nos "[...] jogos de mesa, estes criados por militares no final do século XIX com finalidade de treinamento sob a forma de simulação de situaçõesproblema." (DANIEL MACKAY, 2001 apud CUPERTINO, 2008, p. 21, grifo nosso).

O RPG se constitui em um jogo que possibilita a interpretação de personagens pelos seus jogadores, os quais assumem papéis e criam uma narrativa de forma colaborativa, pilares para a relação ensino-aprendizagem. Trata-se de um jogo em que os personagens vivenciam uma história-aventura, proposta pelo "Mestre" do jogo, o qual ambienta o cenário e o contexto em que todos estão inseridos. (CABALERO, 2012). O Mestre também é responsável por atuar como uma espécie de juiz do jogo, mediando à ação e interação dos jogadores, além de fiscalizar o cumprimento do sistema de regras adotado. (PEIXOTO e PINTO, 2011 apud RIBEIRO, 2016). Por possuir influências da 
linguagem teatral, o jogo de RPG obedece a uma estrutura básica de funcionamento, devendo considerar na sua modelagem os seguintes aspectos que garantem a interatividade do jogo: Ambiente; Sistema de Regras; Enredo; Dados; Mestre; Personagens Jogadores e Classe. (SOUZA, 2016).

O RPG Digital é um software que se constitui em um Ambiente Educacional de Aprendizagem, o qual deve ser modelado a fim de proporcionar um espaço destinado à construção cognitiva e difusão do conhecimento, favorecendo práticas de ensinoaprendizagem baseadas no socioconstrutivismo, que preceitua que a construção do conhecimento é estabelecida através de uma relação dialética entre os sujeitos (personagens jogadores) e o contexto social (ambiente complexo desenvolvido no RPG Digital).

De acordo com os ensinamentos de Matta (2011) podemos entender que:

A proposta socioconstrutivista, ao contrário da construtivista, não se propõe a construir um ambiente capaz de deixar o sujeito imerso em interação desejáveis e construídas, mas sim preparar o sujeito e o que se vai aprender para que participe do ambiente e mundo no qual o sujeito vive. É uma diferença elementar e que nos ajuda a entender as duas. O construtivismo pretende imergir o sujeito no ambiente criado para a aprendizagem, enquanto o socioconstrutivismo pretende engajar a aprendizagem e o processo pedagógico proposto no mundo e no ambiente concreto e cotidiano do sujeito (MATTA, 2011, p. 245).

No RPG Digital a mediação do conhecimento é realizada pelo Mestre do Jogo, desenvolvendo, em uma perspectiva epistemológica vygotskyana, o papel de interlocutor na relação ensino-aprendizagem, na constante interação entre os sujeitos / jogadores, as tecnologias utilizadas e os conteúdos a serem trabalhados colaborativamente, em espécies de campanhas, que se constituem na ambientação proposta pelo jogo.

A aplicabilidade do RPG Digital como recurso tecnológico educacional para simulação de ocorrências policiais militares se justifica em razão de vários aspectos desenvolvidos no jogo, a saber: criatividade dos jogadores, ação colaborativa e tomada de decisões frente às circunstâncias apresentadas, dentre outras características inerentes ao RPG, as quais tornam o aluno mais engajado no processo de construção do conhecimento.

O Grupo de Pesquisa "Sociedade em Rede, Pluralidade Cultural e Conteúdos Digitais Educacionais", vinculado ao DMMDC, desenvolve uma série de produções relacionadas 
ao uso do RPG Digital enquanto recurso educacional. Contudo, a produção de Ribeiro (2016) e de Pontes (2017) merecem destaque.

Ribeiro (2016), em sua tese intitulada "RPG digital e segurança pública: uma proposta de aplicação pedagógica para instrução policial militar", estudou a funcionalidade do RPG Digital como instrumento pedagógico capaz de promover a aprendizagem colaborativa entre os policiais militares do Batalhão Especializado de Polícia Turística (BEPTUR), unidade vinculada à PMBA, através da simulação virtual de ocorrências policiais militares, proporcionando o desenvolvimento de competências e habilidades específicas, uma vez que o ambiente criado estimula a tomada de decisão do profissional, frente a uma situação de colapso apresentada.

Ao analisar a tese de Pontes (2017), intitulada "Objective Team - Role Playing Game para o sistema de apoio a decisão da escola e aperfeiçoamento de Oficiais", nota-se a utilização do RPG enquanto estratégia de aperfeiçoar a capacidade cognitiva de tomada de decisão dos alunos da Escola de Aperfeiçoamento de Oficiais do Exército Brasileiro, durante 0 planejamento de operações militares, onde 0 processo de ensino/aprendizagem se constitui a partir da interação entre os partícipes da pesquisa.

\section{Caminhos da pesquisa}

Tendo em vista o caráter aplicado do estudo descrito, foram realizadas investigações sobre os métodos que mais se adequariam para o seu desenvolvimento, encontrando guarida no artigo intitulado "Design-based Research ou Pesquisa de Desenvolvimento: Metodologia para Pesquisa Aplicada de Inovação em Educação do Século XXI", de autoria dos professores Doutores: Alfredo Eurico Rodrigues Matta, Francisca de Paula Santos da Silva e Edivaldo Machado Boaventura, que descrevem uma metodologia de pesquisa recente, conhecida como Design-Based Research $(D B R)$, a qual se constitui em:

[...] uma inovadora abordagem de investigação que reúne as vantagens das metodologias qualitativas e das quantitativas, focalizando no desenvolvimento de aplicações que possam ser realizadas e de fato integradas às práticas sociais comunitárias, considerando sempre sua diversidade e propriedades específicas, mas também aquilo que puder ser generalizado e assim facilitar a resolução de outros problemas. (MATTA et al, p. 24, 2014).

Os autores ressaltam que a aplicação da $D B R$ tem sido muito usada pelos pesquisadores que investigam as tecnologias digitais, em virtude do seu propósito 
inovador relacionado ao desenvolvimento de práticas pedagógicas mediadas pelas Tecnologias da Informação e Comunicação (MATTA et al, 2014).

O presente estudo conta com o seguinte público alvo: Grupo de policiais militares da $12^{\underline{a}}$ Companhia Independente de Polícia Militar, situada no Bairro do Rio Vermelho; Grupo de alunos do $3^{\circ}$ ano do Curso de Formação de Oficiais da PMBA; Membros do Conselho Tutelar do Bairro do Rio Vermelho; Equipe do Poder Judiciário - Vara da Infância e Juventude; E a equipe da Delegacia para o Adolescente Infrator.

A proposta ora apresentada decorre de uma pesquisa de doutorado em andamento e abrange três fases:

- Desenvolvimento de Procedimentos Operacionais Padrão referentes à atuação policial militar em ocorrências relacionadas ao uso indevido das drogas por crianças e adolescentes, realizados a partir de um esforço dialógico e colaborativo com os partícipes desta pesquisa;

- Modelagem do ambiente virtual de aprendizagem - RPG Digital, desenvolvendo a ambientação, enredo, personagens e demais elementos constituintes do jogo.

- Ciclo de testes do jogo com o grupo de policiais militares acima citados, a fim de verificar a validação interna e a aplicabilidade do jogo no processo de ensinoaprendizagem.

Atualmente a pesquisa se encontra na segunda fase de desenvolvimento e como resultados preliminares pode-se aferir que a criação dos Procedimentos Operacionais Padrão contribui significativamente para a normatização das ações policiais militares dentro de contextos similares, possibilitando a reflexão das melhores decisões a se tomar em um momento de colapso.

Cabe ressaltar que a pesquisa DBR possui como exigência metodológica o teste e refinamento da solução desenvolvida, a fim de tornar mais efetiva sua aplicabilidade, bem como não se constitui em uma pesquisa fechada, possibilitando assim, ao decorrer da pesquisa, a utilização de variados métodos de coleta e análise de dados, com a finalidade de melhor avaliar o estudo.

\section{Considerações parciais}

O estudo descrito neste artigo encontra-se em fase de desenvolvimento, constituindo-se em uma pesquisa aplicada, a ser realizada com a colaboração de diversos atores sociais, com o objetivo em comum de contribuir na prevenção dos problemas 
relacionados ao uso indevido de drogas por crianças e adolescentes, através da qualificação de policiais militares.

O RPG Digital enquanto recurso tecnológico educacional para simulação de ocorrências policiais militares poderá proporcionar a PMBA o desenvolvimento de uma plataforma de amplo alcance, permitindo a formação continuada a um baixo custo de investimento. Contudo, devido às limitações desta pesquisa em desenvolver aplicações relacionadas a outras temáticas do treinamento militar, torna-se necessária a realização de pesquisas análogas, a fim de comprovar a efetividade do RPG digital na qualificação profissional de policiais militares, tornando um instrumento de ensino adotado oficialmente pela Polícia Militar da Bahia.

Assim, esperasse com esta pesquisa apontar possibilidades para a dinamização do processo de ensino dentro da instituição, mediado por ambientes virtuais de aprendizagem, dentro de uma perspectiva epistemológica socioconstrutivista.

\section{REFERÊNCIAS}

BRASIL. Lei no 11.343, de 23 de agosto de 2006. Institui o Sistema Nacional de Políticas Públicas sobre Drogas (Sisnad). Diário Oficial da União. Brasília (DF), p.2, 24 ago. 2006.

CABALERO, Sueli da Silva Xavier (Org). RPG by Moodle. Salvador. 2012. Disponível em < http://www.matta.pro.br/editora_virtual/RPGbyMoodle.pdf> Acesso em 25 abr. 2017.

CUPERTINO, Edson Ribeiro. Vamos jogar RPG? Diálogos com a literatura, o leitor e a autoria. Dissertação (Mestrado) - Programa de Pós-Graduação em Estudos Comparados de Literaturas de Língua Portuguesa, Universidade de São Paulo, São Paulo, 2008, $126 \mathrm{fl}$.

MACRAE, Edward. A história e os contextos socioculturais do uso de drogas. Curso de Prevenção aos Problemas relacionados ao Uso de Drogas. Capacitação para Conselheiros e Lideranças Comunitárias. 2014. 6. ed. Brasília DF. p. 29-42.

MATTA, Alfredo Eurico Rodrigues et al. Design-based research ou pesquisa de desenvolvimento: metodologia para pesquisa aplicada de inovação em educação do século XXI. Revista da FAEEBA - Educação e Contemporaneidade, Salvador, v. 23, n. 42, p. 23-36, jul./dez. 2014. 
Desenvolvimento de metodologia de design socioconstrutivista para a produção do conhecimento. In: GURGEL, Paulo; SANTOS, Wilson. (Org.). Saberes plurais, difusão do conhecimento e práxis pedagógica. 1. ed, Salvador: EDUFBA, 2011, v. 1 , p. $237-258$.

MORAES, C. V. Legislações e políticas para crianças e adolescentes. Curso de Prevenção aos Problemas relacionados ao Uso de Drogas. Capacitação para Conselheiros e Lideranças Comunitárias. 2014. 6. ed. Brasília DF. p. 213-224.

PONTES, Ewerton Carneiro. Objective Team - Role Playing Game para o sistema de apoio a decisão da escola e aperfeiçoamento de oficiais (OT-RPG / SAD-ESAO).Tese (Doutorado) - Universidade Federal da Bahia. Faculdade de Educação, Salvador, 2017, $237 \mathrm{fl}$.

RIBEIRO, Josete Bispo. RPG Digital e Segurança Pública: Uma proposta de aplicação pedagógica para instrução policial militar. Tese (Doutorado) - Universidade Federal da Bahia. Faculdade de Educação, Salvador, 2016, $247 \mathrm{fl}$.

SILVEIRA, D. X; SILVEIRA, E. D. Classificação das substâncias psicoativas e seus efeitos. Curso de Prevenção aos Problemas relacionados ao Uso de Drogas. Capacitação para Conselheiros e Lideranças Comunitárias. 2014. 6. ed. Brasília DF. p. 69-85.

SOUZA, Antonio Lázaro Pereira de. RPG digital instrumento pedagógico para o ensino da abolição da escravidão na Bahia. Dissertação (Mestrado) - Programa de Pós-Graduação em Educação e Contemporaneidade, Universidade do Estado da Bahia, Salvador, 2016, $119 \mathrm{fl}$.

TROJANOWICZ, Robert; BUCQUEROUX, Bonnie. Policiamento comunitário: como começar. 2. ed. São Paulo: Copyright/Polícia Militar do Estado de São Paulo, 1999.

URPIA, Igor Bacelar da Cruz. Políticas públicas sobre drogas no Brasil: um diagnóstico do Programa Educacional de Resistência às Drogas e à Violência da Polícia Militar da Bahia. Dissertação (Mestrado). Programa de Pós-Graduação Gestão e Tecnologias Aplicadas à Educação, Universidade do Estado da Bahia, Salvador, 2017, $123 \mathrm{fl}$. 